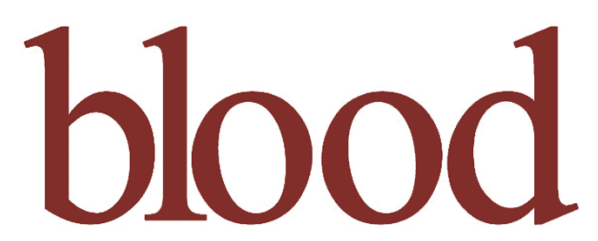

2008 112: 3073-3081

Prepublished online July 29, 2008;

doi:10.1182/blood-2008-03-143412

\title{
The impact of soluble tumor necrosis factor receptor etanercept on the treatment of idiopathic pneumonia syndrome after allogeneic hematopoietic stem cell transplantation
}

Gregory A. Yanik, Vincent T. Ho, John E. Levine, Eric S. White, Thomas Braun, Joseph H. Antin, Joel Whitfield, Joseph Custer, Dawn Jones, James L. M. Ferrara and Kenneth R. Cooke

Updated information and services can be found at:

http://bloodjournal.hematologylibrary.org/content/112/8/3073.full.html

Articles on similar topics can be found in the following Blood collections

Clinical Trials and Observations (3368 articles)

Transplantation (1710 articles)

Information about reproducing this article in parts or in its entirety may be found online at: http://bloodjournal.hematologylibrary.org/site/misc/rights.xhtml\#repub_requests

Information about ordering reprints may be found online at:

http://bloodjournal.hematologylibrary.org/site/misc/rights.xhtml\#reprints

Information about subscriptions and ASH membership may be found online at: http://bloodjournal.hematologylibrary.org/site/subscriptions/index.xhtml

Blood (print ISSN 0006-4971, online ISSN 1528-0020), is published weekly by the American Society of Hematology, 2021 L St, NW, Suite 900 , Washington DC 20036.

Copyright 2011 by The American Society of Hematology; all rights reserved.

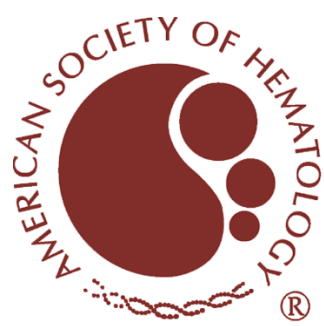




\title{
The impact of soluble tumor necrosis factor receptor etanercept on the treatment of idiopathic pneumonia syndrome after allogeneic hematopoietic stem cell transplantation
}

\author{
Gregory A. Yanik, ${ }^{1,2}$ Vincent T. Ho, ${ }^{3}$ John E. Levine, ${ }^{1,2}$ Eric S. White, ${ }^{4}$ Thomas Braun, ${ }^{5}$ Joseph H. Antin, ${ }^{3}$ Joel Whitfield, ${ }^{1,2}$ \\ Joseph Custer, ${ }^{6}$ Dawn Jones, ${ }^{1,2}$ James L. M. Ferrara, ${ }^{1,2}$ and Kenneth R. Cooke ${ }^{1}$ \\ Departments of ${ }^{1}$ Pediatrics and ${ }^{2}$ Internal Medicine, Blood and Marrow Transplantation Program, University of Michigan, Ann Arbor; ${ }^{3}$ Department of Medical \\ Oncology, Dana-Farber Cancer Institute, Boston, MA; and ${ }^{4}$ Department of Internal Medicine, Division of Pulmonary and Critical Care Medicine, and \\ Departments of ${ }^{5}$ Biostatistics and ${ }^{6}$ Pediatrics, Critical Care Medicine, University of Michigan, Ann Arbor
}

Idiopathic pneumonia syndrome (IPS) refers to a diffuse, noninfectious, acute lung injury after hematopoietic stem cell transplantation. Historically, IPS is associated with respiratory failure and mortality rates exceeding $50 \%$. Preclinical studies have implicated tumor necrosis factor- $\alpha$ as an important effector molecule in the development of disease. We studied the tumor necrosis factor- $\alpha$ inhibitor, etanercept, combined with corticosteroids in treating 15 patients (median age,
18 years; range, 1-60 years) with IPS. Eight of 15 patients required mechanical ventilation at therapy onset. Etanercept was administered subcutaneously at a dose of $0.4 \mathrm{mg} / \mathrm{kg}$ (maximum $25 \mathrm{mg}$ ) twice weekly, for a maximum of 8 doses. Therapy was well tolerated with no infectious pulmonary complications noted. Ten of 15 patients had a complete response, defined as the ability to discontinue supplemental oxygen support during study therapy. The median time to com- plete response was 7 days (range, 3-18 days), with a day 28 survival of $73 \%$. IPS onset was associated with elevations of several inflammatory proteins in the bronchoalveolar lavage fluid and plasma, and response to therapy correlated with reductions in pulmonary and systemic inflammation. The combination of etanercept and corticosteroids is safe and is associated with high response rates and improved survival in patients with IPS. (Blood. 2008;112:3073-3081)

\section{Introduction}

Noninfectious lung injury is a frequent and severe complication of hematopoietic stem cell transplantation (HCT) both in the immediate posttransplantation period and in the months and years that follow. In the acute setting, a diffuse interstitial process, termed idiopathic pneumonia syndrome (IPS), may develop. ${ }^{1-3}$ In 1993, a panel convened by the National Institutes of Health (NIH) proposed a broad working definition of IPS to include widespread alveolar injury in the absence of active lower respiratory tract infection after HCT. ${ }^{1}$ The NIH panel stressed that they considered this definition to be that of a clinical syndrome, with variable histopathologic correlates and several potential etiologies. Diagnostic criteria of IPS include signs and symptoms of pneumonia, nonlobar radiographic infiltrates, abnormal pulmonary function, and the absence of infectious organisms in the lower respiratory tract. ${ }^{1}$

Published reports indicate that IPS develops in $7 \%$ to $15 \%$ of allogeneic HCT patients, a median of 14 to 42 days after transplantation. Survival after onset is poor, with mortality rates of $50 \%$ to $80 \%$ reported. ${ }^{1,4-6}$ The typical clinical course involves a rapid onset of respiratory failure leading to death, underscoring the critical nature of this transplantation-related complication. ${ }^{4}$ Potential etiologies for IPS include direct toxic effects of HCT conditioning regimens, the presence of occult pulmonary infections, and damage from inflammatory cytokines that have been implicated in other forms of pulmonary injury. ${ }^{1,2,6-8}$ Although IPS has been reported after autologous HCT, it is primarily a complication of allogeneic transplantations, suggesting that immunologic factors may be important. ${ }^{3,4,9}$ Furthermore, the development of acute graft-versus- host disease (GVHD) often precedes IPS, a finding that supports a possible causal relationship between these 2 complications. ${ }^{9-11}$

Murine IPS models suggest that the lung is a target of 2 distinct, but interrelated, pathways of immune-mediated injury: 1 involving soluble inflammatory effectors including tumor necrosis factor- $\alpha$ (TNF- $\alpha$ ) and the other driven by antigen specific, donor T-cell effectors. Both pathways synergize to cause inflammation, cellular injury, and pulmonary dysfunction after allogeneic HCT. ${ }^{7}$ Based directly on this preclinical work, we initiated a translational research endeavor using a soluble TNF- $\alpha$-binding protein, etanercept (Enbrel; Amgen, Thousand Oaks, CA), for the treatment of IPS. Etanercept is a dimeric protein consisting of 2 soluble p75 TNF receptors fused to the Fc portion of a type I immunoglobulin molecule. ${ }^{12-14}$ This agent has shown efficacy in multiple clinical trials for the treatment of rheumatoid arthritis and psoriasis ${ }^{15-17}$ and recently has been reported in clinical trials for the treatment of acute and chronic GVHD. ${ }^{18-21}$ Our data show that the combination of etanercept and corticosteroids for treating IPS is associated with high response rates, improved survival, and acceptable toxicity.

\section{Methods}

\section{Patients}

Patients were recruited from the Blood and Marrow Transplantation Programs at the University of Michigan Medical Center and the DanaFarber Cancer Institute between May 2001 and February 2004. Eligible
Submitted March 6, 2008; accepted July 7, 2008. Prepublished online as Blood First Edition paper, July 29, 2008; DOI 10.1182/blood-2008-03-143412.

The publication costs of this article were defrayed in part by page charge payment. Therefore, and solely to indicate this fact, this article is hereby marked "advertisement" in accordance with 18 USC section 1734.

(C) 2008 by The American Society of Hematology 
patients were more than or equal to 1 year in age, recipients of allogeneic HCT and within 100 days of stem cell infusion. All patients had evidence of IPS as defined by NIH working group criteria (Table 1). ${ }^{1}$ There were no restrictions based on underlying disease, stem cell source, transplantation conditioning regimen, or donor-recipient human leukocyte antigen match. Exclusion criteria included the presence of any of the following after at the time of enrollment: (1) an active pulmonary infection as determined by positive culture of bronchoalveolar lavage (BAL) fluid; (2) hypotension in which inotropic support other than dopamine at less than $5 \mu \mathrm{g} / \mathrm{kg}$ per minute was required; (3) bacteremia within 48 hours before study entry; (4) cytomegalovirus (CMV) viremia (by CMV polymerase chain reaction [PCR] or pp65 antigenemia); (5) systemic fungal or other nonbacterial infections; or (6) clinical or echocardiographic evidence for cardiac dysfunction as the cause of respiratory failure. Quantitative bacterial cultures with more than $10^{4} \mathrm{CFU} / \mathrm{mL}$ were considered abnormal on BAL fluid analysis. All patients (or their surrogates) and controls (see "Patient controls") gave written, informed consent in accordance with the Declaration of Helsinki, and the trial was approved by the respective Institutional Review Boards of the University of Michigan and the Dana-Farber Cancer Center.

\section{Patient controls}

Two subject groups served as controls for BAL fluid cytokine studies: (1) HCT recipients with chronic noninfectious pulmonary dysfunction (11 subjects) and (2) healthy volunteers (5 subjects). Patients with chronic noninfectious pulmonary dysfunction were more than 100 days after HCT (median, 965 days), had no evidence for active systemic or lower respiratory tract infection as determined by BAL, and met pulmonary function criteria for either obstructive or restrictive lung disease. Healthy volunteers were subjects with no prior history of transplantation, malignancy, or other significant medical disorder.

Two subject groups served as controls for the plasma cytokine studies: (1) HCT recipients who had an "uncomplicated transplantation course" through day 100 (9 subjects) and (2) from healthy volunteers (7 subjects). Subjects with an "uncomplicated transplantation course" received a myeloablative conditioning regimen and subsequently exhibited no signs of acute GVHD, hepatic veno-occlusive disease, significant infections, or pulmonary dysfunction through day 100 after HCT. Plasma samples were obtained between days 14 and 21 after transplantation in this group of control subjects.

\section{Transplantation protocols}

Conditioning regimen consisted of myeloablative doses of total body irradiation \pm cyclophosphamide or melphalan $(n=5)$, busulfan/cyclophosphamide $(\mathrm{n}=3)$ plus cytarabine $(\mathrm{n}=1)$, cyclophosphamide/BCNU/ etoposide $(\mathrm{n}=3)$, and reduced intensity dosing of cyclophosphamide/total lymphoid irradiation ( $\mathrm{n}=1)$, or fludarabine/busulfan/total lymphoid irradiation $(\mathrm{n}=1)$. Total body irradiation was delivered in 6 fractions $(200 \mathrm{cGy} /$ fraction) over 3 days without lung shielding (or 7 fractions over 4 days with lung shielding). Total lymphoid irradiation was administered in a single 400 cGy fraction. GVHD prophylaxis consisted of tacrolimus plus methotrexate $\left(5 \mathrm{mg} / \mathrm{m}^{2}\right.$ on days $1,3,6$, and 11$)$ in 14 patients, or tacrolimus plus sirolimus in one patient. Acyclovir prophylaxis was given for HSVseropositive patients, and ganciclovir prophylaxis $(5 \mathrm{mg} / \mathrm{kg}$ twice weekly)

Table 1. Idiopathic pneumonia syndrome: diagnostic criteria

1. Widespread alveolar injury
a. Multilobar infiltrates on CXR or CT, PLUS
b. Clinical signs of pneumonia: cough, dyspnea, or rales, PLUS
c. Abnormal physiology: increased arterial-alveolar oxygen gradient, or the need
for supplemental oxygen support
2. Absence of lower respiratory tract infection
a. Negative BAL for bacterial and nonbacterial organisms, OR
b. Negative surgical lung biopsy

The definition of diffuse alveolar hemorrhage (DAH) requires the data in the table, plus progressively bloodier aliquots of lavage fluid noted during bronchoscopy. given days 30 through 100 after HCT if either the patient or donor were CMV seropositive.

\section{Study design}

All patients underwent a chest radiograph, bronchoscopy with BAL, CMV blood assays (CMV PCR or pp65 antigen), aerobic blood cultures, and a clinical assessment of pulmonary dysfunction at the time of study entry. Computed tomography was recommended but not mandated. Assessment of pulmonary function included arterial blood gas measurements, the percentage of inhaled oxygen required to achieve an oxygen saturation $\left(\mathrm{SpO}_{2}\right)$ more than $93 \%$, and $\mathrm{SpO}_{2}$ on ambient air (if not intubated). Chest radiographs were performed twice within the first 7 days of therapy and then weekly through day 28 of study. CMV assays were performed weekly through day 28. Complete blood counts, serum electrolytes, BUN, creatinine, liver function tests, and plasma cytokine analysis were performed at study entry and then weekly through day 28 . Patients who completed the 28-day therapy course underwent a repeat BAL procedure between days 28 and 35 of study. Toxicity assessments, duration of supplemental oxygen support, day 28 survival, and overall survival were recorded.

\section{Bronchoalveolar lavage}

BAL fluid samples were collected in a systematic fashion. During bronchoscopy, a maximum of $2 \mathrm{~mL} / \mathrm{kg}$ (total) of normal saline were sequentially instilled and aspirated from right- and left-sided lung segments, pooled, and subsequently divided for the following studies: cell count and cytospin, cytopathology, infectious disease studies, and protein analysis. An aliquot of fluid was strained through sterile gauze, and cytospin slides were also prepared for cellular differential and microbiologic assessment. Infectious disease studies included gram stain, fungal stain, stain for acid-fast bacilli; quantitative bacterial culture, viral cultures for respiratory syncytial virus, parainfluenza, adenovirus, influenza $\mathrm{A}$ and $\mathrm{B}$, herpes simplex virus, and $\mathrm{CMV}$; shell vial CMV culture; fungal and mycobacterial cultures, and PCR for Pneumocystis carinii pneumonia. Lavage fluid was also collected and later analyzed in batch for a panel of inflammatory proteins (see "Determination of protein levels by ELISA"). For these analyses, BAL fluid was centrifuged at $350 \mathrm{~g}$ for 10 minutes, and the cell free supernatants were aliquoted, frozen, and stored at $-80^{\circ} \mathrm{C}$.

\section{Plasma samples}

Blood for inflammatory cytokine analysis was obtained at study entry and then weekly through day 28. Blood was collected in heparinized tubes and transported to the University of Michigan Cancer Center Immunology Core Laboratory for processing. The plasma compartment was separated, divided, and stored at $-80^{\circ} \mathrm{C}$ as per standard operating procedures, until the time of analysis. In addition, plasma samples were obtained before transplantation (before conditioning therapy) for inflammatory cytokine analysis in patients who had signed informed consent for such sample acquisition.

\section{Determination of protein levels by ELISA}

Frozen BAL fluid and plasma samples were thawed and analyzed in batch for a panel of inflammatory proteins including TNF- $\alpha$, TNFRI, TNFRII, sCD-14, interleukin-1- $\beta$ (IL-1- $\beta$ ), IL-1ra, transforming growth factor- $\beta$ (TGF- $\beta$; BioSource International, Camarillo, CA), interferon- $\gamma$ (IFN- $\gamma$ ), IL-2, IL-6, IL-8, MCP-1 (BD BioSciences PharMingen, San Diego, CA), MIG/CXCL9 (R\&D Systems, Minneapolis, MN), lipopolysaccharide binding protein (Cell Sciences, Canton, MA). Enzyme-linked immunosorbent assays (ELISAs) were performed as per the manufacturer's guidelines in the Immunology Core Laboratory at the University of Michigan Medical Center. All samples and controls were run in duplicate. Limits of detection for individual assays are as follows: TNF- $\alpha(1 \mathrm{pg} / \mathrm{mL})$, TNFRI $(50 \mathrm{pg} / \mathrm{mL})$, TNFRII (100 pg/mL), sCD-14 (1 ng/mL), IL-1- $\beta$ (1 pg/mL), IL-1 ra (4 pg/mL), TGF- $\beta$ ( $2 \mathrm{pg} / \mathrm{mL}), \mathrm{IFN}-\gamma(1 \mathrm{pg} / \mathrm{mL}), \mathrm{IL}-2(4 \mathrm{pg} / \mathrm{mL}), \mathrm{IL}-6$ (2.5 pg/mL), IL-8 (1 pg/mL), MCP-1(1 pg/mL), MIG/CXCL9 $(5 \mathrm{pg} / \mathrm{mL})$, and lipopolysaccharide binding protein $(0.1 \mathrm{ng} / \mathrm{mL})$. 


\section{Etanercept therapy}

Etanercept therapy was initiated a minimum of 24 hours after the BAL procedure, provided that BAL fluid special stains (gram, fungal, and acid fast bacilli) were negative. Etanercept was reconstituted from a lyophilized powder and administered subcutaneously at a dose of $0.4 \mathrm{mg} / \mathrm{kg}$ (maximum dose, $25 \mathrm{mg}$ ), twice weekly (72-96 hours between doses), for a maximum total of 8 doses (4-week course). No dosing adjustments were made based on renal or hepatic function. No premedication was administered. All patients were observed for local reactions at the injection site within 30 minutes of a dose. Vital signs, including temperature, blood pressure, heart rate, and respiratory rate, were recorded before and then at 15 and 30 minutes after each dose. Etanercept therapy was discontinued, and not reinstituted, if any one of the following criteria were subsequently met during the course of therapy: (1) prestudy BAL fluid cultures became positive for a pathogenic organism, (2) the patient developed clinical signs of sepsis syndrome, (3) inotropic support (other than dopamine at $<5 \mu \mathrm{g} / \mathrm{kg}$ per minute) was required, (4) the patient developed CMV viremia or CMV disease, or (5) the patient became bacteremic, based on the presence of one (or more) positive blood culture(s) for a potentially pathogenic organism.

\section{Concurrent immunosuppressive therapy}

All patients received systemic corticosteroids at the time of study entry. Corticosteroids were administered at $2 \mathrm{mg} / \mathrm{kg}$ per day (methylprednisolone equivalent) for the initial 7 days of study therapy and then tapered as clinically indicated. Dosing adjustments for tacrolimus or cyclosporine were allowed based on measurement of serum drug levels. Other immunosuppressive agents were to continue throughout the study therapy, without dosing adjustment, unless clinically warranted.

\section{Statistical analysis}

Response was defined as the ability to completely discontinue all supplemental oxygen support within the 28 -day study period. The "time to response" was defined as the first of 3 consecutive days in which a patient exhibited a $\mathrm{SpO}_{2}$ more than $93 \%$ off all supplemental oxygen support. Patients who failed to discontinue oxygen support within the 28-day period, those who died from IPS or non-IPS-related causes (by day 28) were counted as nonresponders. The "time to onset of IPS" was defined as the initial day in which both the radiographic features of IPS plus supplemental oxygen support were noted. Neutrophil engraftment was defined as the first of 3 consecutive days with an absolute neutrophil count (ANC) more than $500 / \mu \mathrm{L}$. Platelet engraftment was defined as the first of 3 consecutive days with a platelet count more than $20000 / \mu \mathrm{L}$ without transfusional support. Overall survival was computed using the Kaplan-Meier method. Statistical comparisons of plasma and BAL fluid protein data were completed using a Student $t$ test.

\section{Results}

\section{Patient demographics and BAL procedure}

Fifteen patients (median, 21 years; range, 1-60 years) meeting the diagnostic criteria for IPS were enrolled (Table 2). Thirteen of 15 patients received a myeloablative conditioning regimen, and 2 received a total lymphoid irradiation-based reduced-intensity regimen. Thirteen of 15 patients received an HCT from an unrelated donor, and the remaining 2 patients received transplants using a matched related donor. Hematopoietic cell sources included peripheral stem cells (7), bone marrow (7), and cord blood (1). At diagnosis, 9 patients exhibited grades II to IV acute GVHD (grades III and IV in 3). Eleven patients had engrafted neutrophils and 9 had engrafted platelets at the time of study entry. The median ANC was $1235 / \mu \mathrm{L}$ (range, $100-39100 / \mu \mathrm{L}$ ), median platelet count

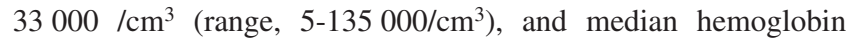
$9.3 \mathrm{~g} / \mathrm{dL}$ (range, $7.9-10.5 \mathrm{~g} / \mathrm{dL}$ ) at study entry. Four patients were neutropenic $(\mathrm{ANC} \leq 500 / \mu \mathrm{L})$, and 6 exhibited a platelet count less than or equal to $20000 / \mathrm{cm}^{3}$. Cardiac failure was excluded by

Table 2. Clinical characteristics: Patient demographics, status at study entry, response, and toxicity

\begin{tabular}{|c|c|c|c|c|c|c|c|c|c|c|c|c|c|c|c|}
\hline Patient no. & 1 & 2 & 3 & 4 & 5 & 6 & 7 & 8 & 9 & 10 & 11 & 12 & 13 & 14 & 15 \\
\hline \multicolumn{16}{|l|}{ Demographics } \\
\hline Age, $y$ & 21 & 31 & 1 & 13 & 9 & 29 & 15 & 43 & 29 & 20 & 7 & 60 & 11 & 34 & 32 \\
\hline Sex & M & M & $M$ & $\mathrm{~F}$ & $\mathrm{~F}$ & M & M & $M$ & $\mathrm{~F}$ & $\mathrm{~F}$ & M & M & $\mathrm{F}$ & M & $\mathrm{F}$ \\
\hline Diagnosis & $\mathrm{NHL}$ & $\mathrm{AML}$ & Imm & ALL & MDS & $\mathrm{NHL}$ & ALL & $\mathrm{CML}$ & ALL & $\mathrm{NHL}$ & ALL & $\mathrm{NHL}$ & AA & CML & MDS \\
\hline HLA match & $6 / 6$ & $5 / 6$ & $6 / 6$ & $6 / 6$ & $6 / 6$ & $5 / 6$ & $6 / 6$ & $6 / 6$ & $6 / 6$ & $6 / 6$ & $6 / 6$ & $6 / 6$ & $6 / 6$ & $5 / 6$ & $6 / 6$ \\
\hline Donor type & MRD & URD & URD & URD & URD & URD & URD & URD & URD & URD & URD & URD & URD & URD & MRD \\
\hline Donor cells & PSC & PSC & Cord & $\mathrm{BM}$ & BM & $\mathrm{BM}$ & $\mathrm{BM}$ & PSC & PSC & PSC & BM & PSC & $\mathrm{BM}$ & $\mathrm{BM}$ & PSC \\
\hline Conditioning & CBV & MTBI & BuCy & СутВІ & BuCy & CBV & BAC & СутВІ & СутВі & CVB & СуТВІ & BuFI & CyTLI & BuCy & СутВ \\
\hline \multicolumn{16}{|l|}{ Status at study entry } \\
\hline Acute GVHD & Yes & Yes & Yes & Yes & Yes & No & Yes & No & No & No & Yes & No & No & Yes & Yes \\
\hline Prior steroids, $d$ & 4 & 1 & 28 & 3 & 0 & 9 & 2 & 0 & 2 & 8 & 2 & 2 & 0 & 7 & 3 \\
\hline Prior $\mathrm{O}_{2}, \mathrm{~d}$ & 2 & 4 & 3 & 1 & 1 & 12 & 2 & 2 & 3 & 5 & 3 & 6 & 3 & 7 & 1 \\
\hline IPS onset, date & +19 & +10 & +56 & +12 & +12 & +9 & +11 & +15 & +13 & +13 & +14 & +83 & +17 & +87 & +19 \\
\hline Initiation study treatment & +23 & +11 & +58 & +13 & +13 & +15 & +12 & +17 & +16 & +21 & +16 & +87 & +20 & +94 & +20 \\
\hline Intubated (at entry) & Yes & Yes & No & No & No & Yes & No & No & Yes & Yes & No & Yes & No & No & Yes \\
\hline \multicolumn{16}{|l|}{ Response } \\
\hline Clinical response & CR & CR & CR & CR & CR & NR & CR & CR & NR & NR & NR & NR & CR & CR & CR \\
\hline Total doses until CR & 3 & 5 & 2 & 2 & 1 & NA & 2 & 5 & NA & NA & NA & NA & 3 & 2 & 1 \\
\hline No. days until off $\mathrm{O}_{2}$ & 8 & 17 & 5 & 4 & 3 & NA & 5 & 16 & NA & NA & NA & NA & 10 & 4 & 17 \\
\hline Overall survival & 148 & 233 & 199 & 238 & +1425 & 7 & +1344 & 67 & 17 & 18 & 55 & 4 & 46 & 62 & +705 \\
\hline Cause of death & Rel & GVH & CF & GVH & - & IPS & - & INF & IPS & IPS & IPS & IPS & INF & INF & - \\
\hline Toxicity: infections & - & - & - & - & - & Bact & - & Bact & - & - & - & Bact & CMV & Fungal & - \\
\hline
\end{tabular}

$\mathrm{NHL}$ indicates non-Hodgkin lymphoma; AML, acute myelogenous leukemia; Imm, congenital immune disorder; ALL, acute lymphoblastic leukemia; CML, chronic myelogenous leukemia; MDS, myelodysplastic syndrome; URD, unrelated donor; MRD, matched related donor; BM, bone marrow; PSC, peripheral stem cells; Prior steroids, number of days that a patient was on corticosteroids prior to study entry; Prior $\mathrm{O}_{2}$, number of days that a patient required supplemental oxygen support prior to study entry; $\mathrm{CBV}$, cyclophosphamide, busulfan, VP16; MTBI, melphalan, total body irradiation; BuCy, busulfan, cyclophosphamide; BuFlu, busulfan, fludarabine; CyTLI, cyclophosphamide, total lymphoid irradiation; CR, complete response; NR, nonresponder; Rel, relapsed malignancy; CF, cardiac failure; INF, infection; Bact, bacteremia; and —, not applicable. 

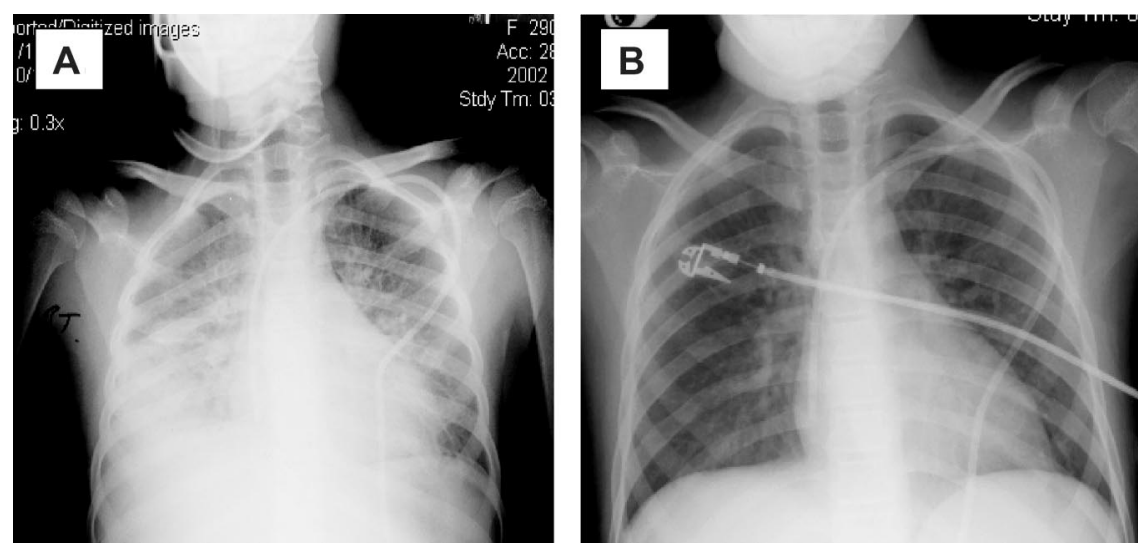

Figure 1. Chest radiographs of patient 5. (A) Before therapy. (B) On therapy. Panel A was obtained on day 0 of study, with the patient requiring $100 \% \mathrm{FiO}_{2}$ via bilevel positive airway pressure (BiPAP). Panel B was obtained 3 days later, with the patient now off all supplemental oxygen support.

echocardiogram (5 patients) or by clinical examination (10 patients). All patients exhibited either a negative CMV shell vial or negative CMV PCR blood assay at the time of study entry.

The median time to onset of IPS was 14 days (mean, 26 days; range, 9-87 days) after transplantation. In most cases $(n=11)$, IPS developed within 7 days of engraftment. Twelve patients were being treated with corticosteroids for a median of 6 days (range, 1-28 days) before study enrollment. Eight patients required mechanical ventilation at the time treatment was initiated. Four patients were on mechanical ventilation for more than or equal to 48 hours at study entry, with inspired oxygen concentrations ranging between $55 \%$ and $100 \%$. The duration of supplemental oxygen support ranged from 1 to 12 days (median, 3 days) before beginning etanercept therapy. Diuretics were administered to all patients at the time of study entry. The median weight change from baseline (admission) to study entry was $+2.2 \mathrm{~kg}$ (range, $0-8.7 \mathrm{~kg}$ ), and weight increased from baseline in 13 of 15 cases.

The pretherapy bronchoscopy was overall well tolerated, with no significant complications attributable to the procedure. No patient required persistent mechanical ventilation as a direct consequence of the BAL procedure. Diffuse alveolar hemorrhage (DAH) was suspected in 2 patients (patients 9,10) as determined by the presence of increasingly bloodier lavage returns during bronchoscopy. Etanercept was initiated a median of 2 days (range, 1-4 days) after bronchoscopy. Six responding patients underwent a second BAL procedure within 7 days of completion of etanercept therapy (days 28-35), and lavage fluid was available for cytokine analysis in 5 of these patients.

\section{Clinical response}

The introduction of etanercept was associated with a reduction in oxygen requirement in 13 patients, and in 10 patients a complete response (CR) to therapy was achieved (Table 2). Clearing of radiographic infiltrates accompanied clinical responses (Figure 1). The median time to $\mathrm{CR}$ was 7 days (range, 3-17 days), with a median of 2 etanercept doses (mean, 3 doses; range, 1-5 doses) required to achieve a CR. Two patients achieved CR after the first dose, and 4 achieved CR after the second dose of etanercept. Three of $8(38 \%)$ patients on mechanical ventilation at initiation of etanercept therapy achieved a CR. Patients were more likely to have a CR if etanercept was started early after the onset of clinical IPS symptoms. For the 10 responding patients, therapy was initiated a median of 1 day from the diagnosis of IPS, compared with a median of 3 days in the 5 treatment failures. Although small numbers preclude statistical analysis, the 5 patients who did not achieve CR had a longer duration of severe symptoms (4 of 5 were mechanically ventilated $\geq 48$ hours) at study entry.
Weight change (before therapy vs after therapy) was not predictive of response. Seven subjects (4 responders, 3 nonresponders) had a decrease in weight (median, $-2.8 \mathrm{~kg}$ ) during study therapy. Five subjects ( 3 responders, 2 nonresponders) had an increase in weight (median, $+0.9 \mathrm{~kg}$ ) with therapy. The 3 remaining patients (all responders) had no change in weight between study entry and the end of study therapy.

\section{Toxicity and survival}

Etanercept therapy was well tolerated, with no episodes of sepsis syndrome or pulmonary infections noted while on study therapy (Table 2). Eight patients completed the 4-week course of therapy. In the remaining 7 patients, etanercept was discontinued because of the development of bacteremia ( $n=3)$, CMV viremia $(n=1)$, dermatologic toxicity $(n=1)$, progressive multiorgan failure $(n=1)$, and growth of rhinovirus from the prestudy BAL fluid $(\mathrm{n}=1)$. Bacteremic episodes were the result of Enterococcus faecalis $(\mathrm{n}=2)$ or Staphylococcus epidermis $(\mathrm{n}=1)$. One patient (patient 15$)$ developed a bullous dermatitis on the left upper extremity outside the injection site region 48 hours after the initial etanercept dose. Although the patient subsequently had a complete response, this was considered a dose-limiting toxicity, and etanercept was discontinued in this patient. A total of 81 etanercept doses were given to the 15 patients, with no infusionrelated, injection site, or other cutaneous toxicities noted.

Overall survival is shown in Figure 2. Survival at day 28 and day 56 (from the first etanercept dose) was $73 \%$ and $60 \%$, respectively. Patients requiring less than 48 hours of mechanical ventilation before study entry had a median survival of 150 days (range, 46-1425 days), compared with 17 days (range, 3-148 days) for patients requiring mechanical ventilation more than or equal to 48 hours before study entry. Cause of death included progression of

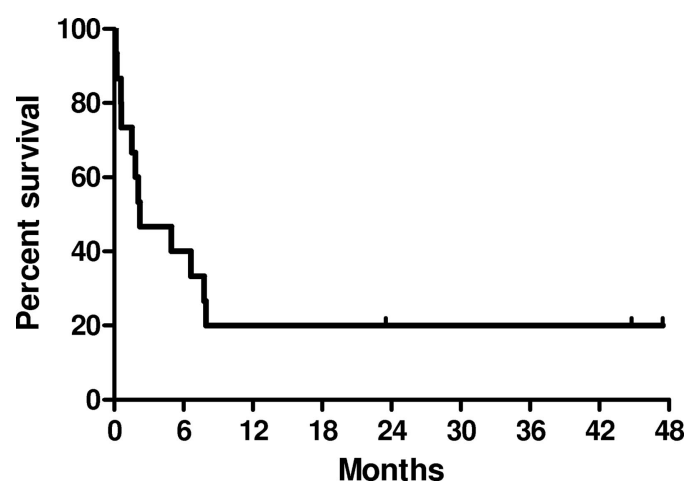

Figure 2. Kaplan-Meier estimates of overall survival after etanercept and corticosteroids for IPS. 
IPS ( $\mathrm{n}=5)$, later-onset (after therapy) infectious etiologies $(\mathrm{n}=3)$, GVHD $(n=2)$, cardiac failure $(n=1)$, and disease relapse $(\mathrm{n}=1)$. Three patients remain alive, 705 to 1425 days after therapy (Table 2).

\section{Proteomic analysis of BAL fluid and plasma}

As shown in Figure 3 and Table 3, the development of IPS was associated with a significant increase in BAL fluid concentrations of several inflammatory mediators, including TNF- $\alpha$, sTNFRI, sTNFRII, IL-6, sCD14, lipopolysaccharide binding protein (LBP), IL-1ra, IL-8, MCP-1, and total protein, compared with normal controls and allogeneic HCT recipients with noninfectious, chronic lung injury. By contrast, concentrations of IL-1- $\beta$, IL-2, and IFN- $\gamma$ were not appreciably altered in patients with IPS, and levels of TGF- $\beta$ were undetectable. Of the 10 patients who responded, 6 underwent a second BAL procedure at the end of the study period, and samples from 5 of these patients were available for protein analysis. As shown in Table 3, clinical response to therapy correlated with statistically significant reductions in BAL fluid concentrations of TNF- $\alpha$, sTNFRI, sTNFRII, IL-6, sCD14, LPB, IL-8, MCP-1, and total protein.

A similar proteomic profile was examined in the plasma of study patients. In this set of experiments, analysis of patient pre-HCT samples, along with plasma collected between days 14 and 21 from allogeneic HCT recipients without complications, were also included as controls. As shown in Figure 4 and Table 4, the development of IPS was associated with high plasma concentrations of each protein measured with the exception of IL-1- $\beta$, IL-2, and IFN- $\gamma$. Of note, no differences in plasma protein concentrations were noted at the time of diagnosis among patients who ultimately responded or failed to respond to etanercept therapy (Table 4). In accord with previous work in patients with acute GVHD, ${ }^{19,21,22}$ sTNFRI levels represented a surrogate marker of systemic inflammation associated with both the onset of IPS and response to therapy (Figure 5). Similar findings were observed with respect to IL-6, sCD14, LBP, and MCP-1 (Table 4). By contrast, plasma protein levels continued to rise or showed no significant decrease in the single nonresponding patient who survived to the end of the 28-day study period (data not shown). Plasma sTNFRII levels were markedly increased in responding patients at the end of therapy, consistent with the measurement of systemically administered etanercept (rhTNFR:Fc).

\section{Discussion}

IPS is a frequently fatal complication after allogeneic HCT, with a $7 \%$ to $15 \%$ incidence in the first 120 days after full-intensity conditioning. ${ }^{3-6}$ The median time of onset is between the second and third weeks after HCT., ${ }^{4,5}$ Clinical outcomes for patients with
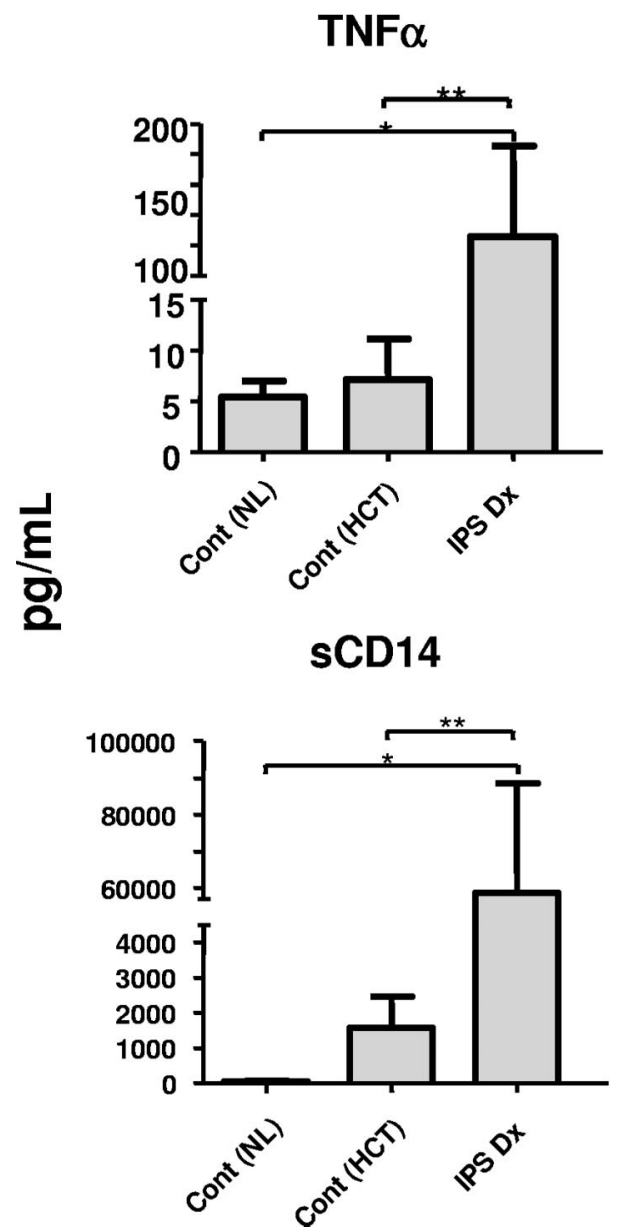

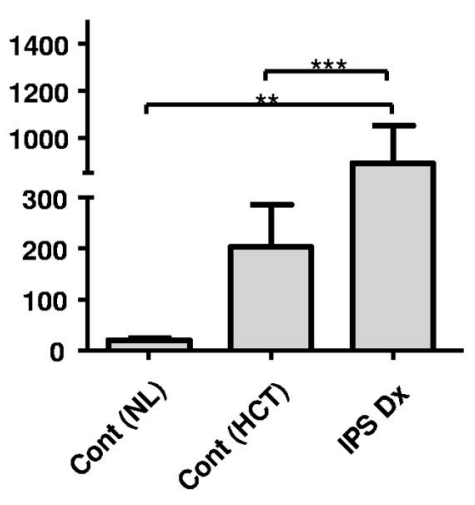

MCP-1 (CCL2)

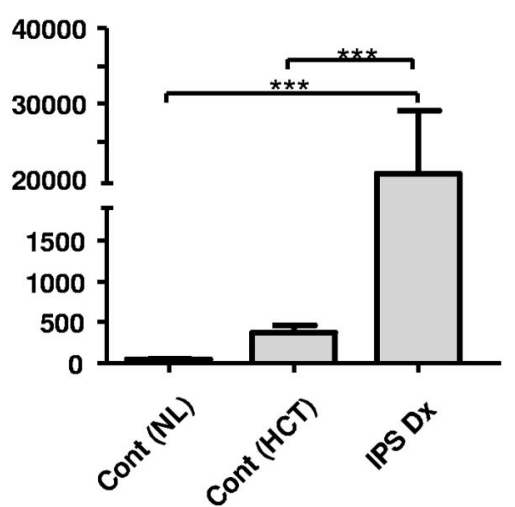

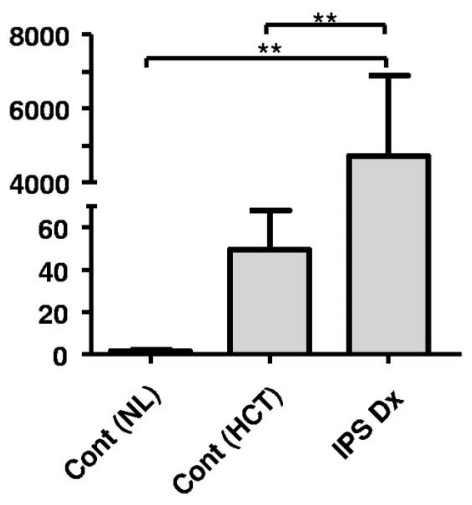

IFN $\gamma$

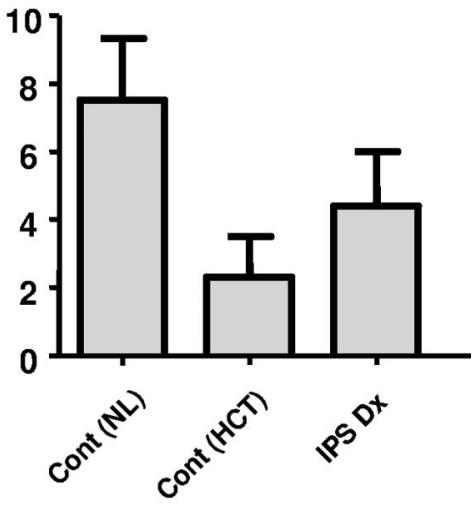

Figure 3. BAL fluid protein profiles. BAL fluid protein levels were measured from samples collected at the time of IPS diagnosis (IPS-Dx) and compared with levels found in BAL fluid obtained from healthy persons not receiving transplants (Cont (NL)), and HCT recipients with chronic noninfectious lung dysfunction (Cont (HCT)) as described in "Patient controls." BAL fluid levels of total protein and several inflammatory mediators were elevated at the time of IPS. Data are expressed as mean plus or minus SEM. Significant differences between specific groups are shown; $\mathrm{n}=5$ to 14 per group. 
From bloodjournal.hematologylibrary.org at UNIV OF MICHIGAN on December 16, 2011. For personal use only.

Table 3. BAL fluid protein profiles at study onset and completion

\begin{tabular}{|c|c|c|c|c|c|c|c|c|}
\hline & \multirow[b]{2}{*}{ No. } & \multicolumn{3}{|c|}{ TNF- $\alpha$ and soluble receptors } & \multicolumn{2}{|c|}{ Proinflammatory cytokines } & \multicolumn{2}{|c|}{ T-cell cytokines } \\
\hline & & TNF- $\alpha, p g / m L$ & TNFRI, pg/mL & TNFRII, pg/mL & IL-6, pg/mL & $\mathrm{IL}-1 \beta, \mathrm{pg} / \mathrm{mL}$ & $\mathrm{IL}-2, \mathrm{pg} / \mathrm{mL}$ & INF- $\gamma, \mathrm{pg} / \mathrm{mL}$ \\
\hline Control & 5 & $5.4 \pm 1.6$ & $21 \pm 3$ & $16 \pm 0.8$ & $1.6 \pm 0.7$ & $1.3 \pm 0.5$ & $2.6 \pm 1.1$ & $7.5 \pm 1.8$ \\
\hline IPS-Dx (All) & 11 & $126 \pm 59^{\star}$ & $892 \pm 158^{\star}$ & $1071 \pm 278^{*}$ & $4715 \pm 2167^{*}$ & $7.1 \pm 3.6$ & $10.7 \pm 4.8$ & $4.4 \pm 1.6$ \\
\hline IPS-Dx (NR) & 3 & $215 \pm 69$ & $1345 \pm 215$ & $2007 \pm 670$ & $5115 \pm 3388$ & $6.3 \pm 3.8$ & $16.7 \pm 9.5$ & $11.3 \pm 2.3$ \\
\hline IPS-Dx (Resp) & 5 & $144 \pm 120$ & $846 \pm 232$ & $826 \pm 240$ & $6219 \pm 3800$ & $10.6 \pm 7.7$ & $4.1 \pm 2.3$ & $1.2 \pm 1.2$ \\
\hline \multirow[t]{3}{*}{ IPS-post (Resp) } & 5 & $12 \pm 2 \dagger$ & $157 \pm 53 \S$ & $362 \pm 144 \dagger$ & $4.4 \pm 0.7 \ddagger$ & $1.5 \pm 0.6$ & $0.8 \pm 0.8$ & $1.5 \pm 1.0$ \\
\hline & & \multicolumn{2}{|c|}{ LPS activation cascade } & \multicolumn{2}{|c|}{ Anti-inflammatory cytokines } & \multicolumn{2}{|c|}{ Proinflammatory chemokines } & Capillary leak \\
\hline & & $\mathrm{sCD} 14, \mathrm{ng} / \mathrm{mL}$ & LBP, ng/mL & IL-1ra, pg/mL & TGF- $\beta, \mathrm{pg} / \mathrm{mL}$ & IL-8, pg/mL & $\mathrm{MCP}-1, \mathrm{pg} / \mathrm{mL}$ & Protein, $\mu \mathrm{g} / \mathrm{mL}$ \\
\hline Control & 5 & LOD & UD & $94 \pm 17$ & UD & $32 \pm 5.8$ & $43 \pm 10$ & $59 \pm 5$ \\
\hline IPS-Dx (All) & 11 & $59 \pm 30^{*}$ & $0.6 \pm 0.4^{*}$ & $2513 \pm 1306^{*}$ & UD & $2373 \pm 1295^{*}$ & $20784 \pm 8304^{*}$ & $1845 \pm 357^{*}$ \\
\hline IPS-Dx (NR) & 3 & $106 \pm 106$ & $0.2 \pm 0.8$ & $1220 \pm 610$ & UD & $2030 \pm 1117$ & $33235 \pm 20333$ & $2219 \pm 176$ \\
\hline IPS-Dx (Resp) & 5 & $64 \pm 25$ & $1.1 \pm 0.8$ & $3746 \pm 2600$ & UD & $4069 \pm 2450$ & $32647 \pm 15266$ & $2358 \pm 505$ \\
\hline IPS-post (Resp) & 5 & $2.9 \pm 1.2 \ddagger$ & UD‡ & $821 \pm 262$ & UD & $545 \pm 375 \dagger$ & $1060 \pm 777 \dagger$ & $505 \pm 46 \ddagger$ \\
\hline
\end{tabular}

Protein levels were measured in the BAL fluid collected from all subjects with IPS at the time of diagnosis (IPS-Dx [AII]) and compared BAL fluid levels in normal individuals (Control). For the 5 subjects who achieved CR and underwent a second BAL procedure, data are provided at the time of initial IPS diagnosis (IPS-Dx [Resp]) and at the end of study therapy (IPS-post [Resp]). Data are as mean plus or minus SEM. No differences were observed in BAL protein levels between responders and nonresponders at the time of diagnosis, IPS-Dx (Resp) versus IPS-Dx (NR).

Resp indicates responders; UD, undetectable; and LOD, limits of detection.

${ }^{\star} P<.01$ : IPS-Dx (All) vs Control.

$\dagger P<.05$ IPS-post (Resp) vs IPS-Dx (Resp).

$\ddagger P<.01$ IPS-post (Resp) vs IPS-Dx (Resp).

IPS have been poor, with mortality rates ranging from $50 \%$ to $80 \%$ overall, and the median time from diagnosis to death as short as 13 days. ${ }^{3-5}$ The definition of IPS encompasses a heterogeneous group of descriptive disorders that are associated with diffuse alveolar damage or an interstitial pneumonitis (reviewed by Cooke and Yanik $^{7}$ ). DAH is viewed as a subset IPS, in which acute pulmonary hemorrhage associated with hemorrhagic alveolitis is present. Clinically, DAH is defined by the demonstration of progressively bloodier aliquots of BAL fluid (typically without frank hemoptysis) in the context of progressive shortness of breath, cough, and hypoxemia with or without fever. ${ }^{8,23-26}$ Periengraftment respiratory distress syndrome also falls within the clinical spectrum of IPS, and is characterized by fever, dyspnea, and hypoxemia that occur with engraftment after an autologous or allogeneic transplantation. ${ }^{7,8}$ Although peri-engraftment respiratory distress syndrome may occur after either autologous or allogeneic HCT, the 2 entities differ distinctly with respect to overall outcome..$^{4,27,28}$ In the patients reported in this study, 2 patients met criteria for DAH and 11 of 15 (73\%) patients developed IPS within 7 days of engraftment.

Risk factors for IPS consistently include conditioning with total body irradiation, older recipient age, and the development of severe GVHD, ${ }^{4,6,9,29}$ and the likelihood of developing IPS increases with the number of identified risk factors. ${ }^{29}$ Recently, the cumulative incidence of IPS was found to be significantly lower after nonmyeloablative conditioning than observed after full-intensity conventional conditioning. ${ }^{6}$ Once established, however, pulmonary toxicity was severe and resulted in significant mortality in each group. These findings suggest that the intensity of HCT conditioning plays an important role in the development of IPS, as has been shown in mouse models of disease. ${ }^{30,31}$ In a retrospective analysis performed at the University of Michigan, the incidence of IPS after allogeneic SCT ranged from $5 \%$ to $20 \%$, depending on the donor source and the degree of antigenic mismatch between donor and host. ${ }^{5}$ In this context, BMT recipients of mismatched, unrelated donors had the highest risk of developing IPS. Collectively, these data suggest that unrelated donor BMT patients receiving full intensity conditioning with total body irradiation may be at particularly high risk of developing IPS. It is anticipated that the completion of an ongoing phase 3 Bone Marrow TransplantClinical Trials Network trial will better define the impact that such factors have on prognosis.

The association between IPS and severe GVHD that has been reported in several large series, ${ }^{3,4,8,9,29}$ along with the development of reproducible lung injury in rodents with GVHD, ${ }^{30,32-34}$ suggest that immunologic factors may also be important in the pathophysiology of IPS. The development of acute GVHD may precede IPS, suggesting a possible causal relationship between the 2 disorders. ${ }^{9-11}$ In the current trial, 9 of 15 patients exhibited acute GVHD at the onset of study therapy. Six of the 9 had resolution of their GVHD within the 28-day study period. Whether IPS represents a severe form of lung GVHD or simply a severe sequelae of cytokine activation associated with acute GVHD remains a topic of considerable debate and ongoing investigation. ${ }^{7}$

Studies using animal IPS models have provided valuable insights into the pathogenesis of this disorder. Pulmonary inflammation observed in mice with GVHD is accompanied by significant increases in TNF- $\alpha$ levels both in lung tissue and BAL fluid. . $3,35,36^{-3}$ Furthermore, a causal role for TNF- $\alpha$ in the development of experimental IPS has been established using neutralization strategies ${ }^{37,38}$ and TNF- $\alpha$-deficient mice as HCT donors. ${ }^{36,39}$ The actions of TNF- $\alpha$ are mediated by 2 receptors: a $55-$ to $60-\mathrm{kDa}$ type I receptor (TNFRI; p55/60; CD120a) and a 75- to 80-kDa type II receptor (TNFRII; p75/80; CD120b). ${ }^{40-42}$ Both receptors are coexpressed in almost every cell in the body and exist as membranebound proteins that can be shed to circulate as soluble receptors in the context of inflammation. Indeed, concentrations of both sTNFRI and sTNFRII were markedly increased in the plasma and BAL fluid of patients with IPS in accord with earlier studies in humans and mice., ${ }^{2,43}$ We have recently shown that TNFRII expression on host tissues contributes to the development of experimental IPS; the absence of TNFRII in murine allogeneic $\mathrm{HCT}$ recipients is associated with a decrease in the severity of lung injury. ${ }^{44}$

Consistent with previous reports on clinical and experimental IPS, patients in this study showed evidence for pulmonary vascular injury and leak as demonstrated by pulmonary edema and increased BAL fluid total protein levels at the time of diagnosis 
TNF $\alpha$

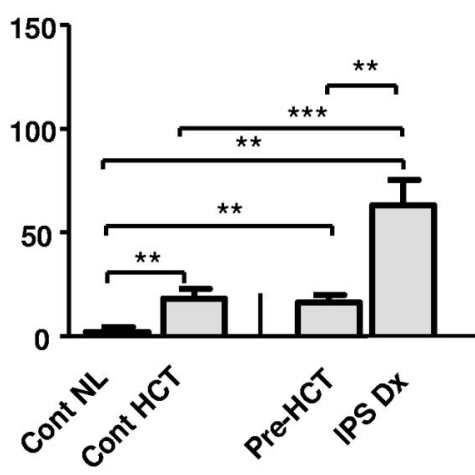

SCD14

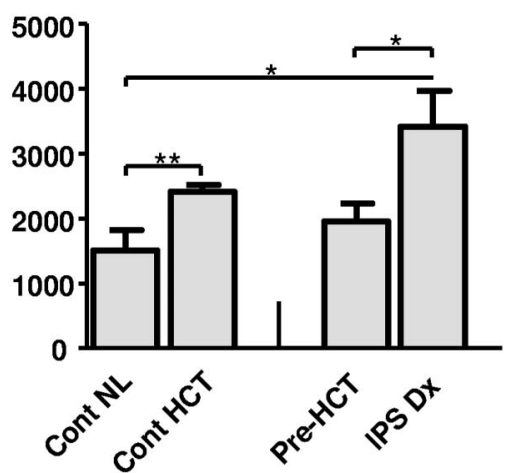

TNFRI

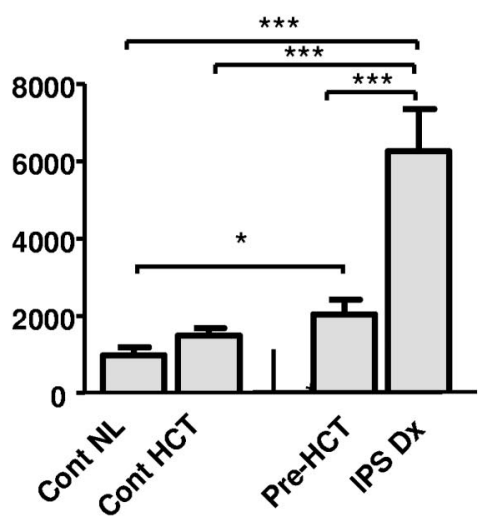

MCP-1

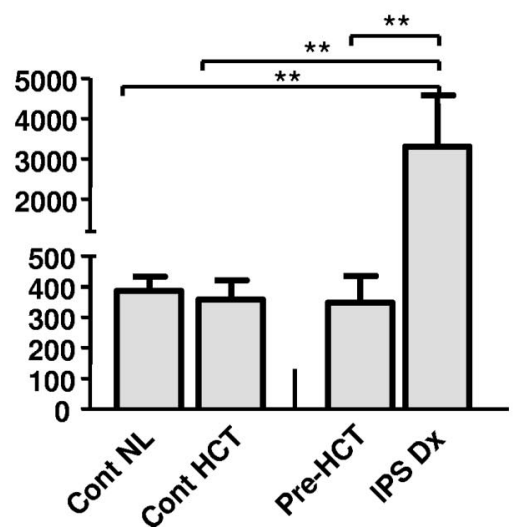

IL-6

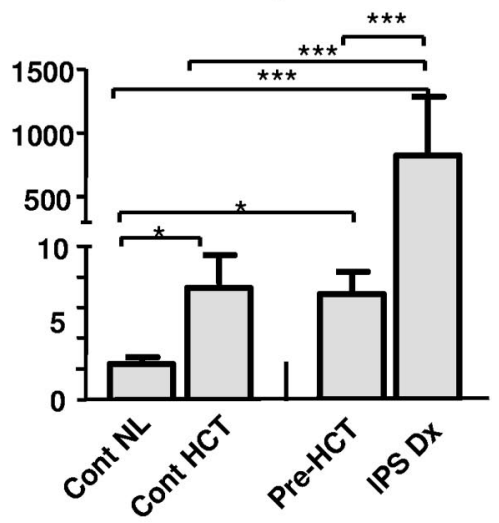

IFN $\gamma$

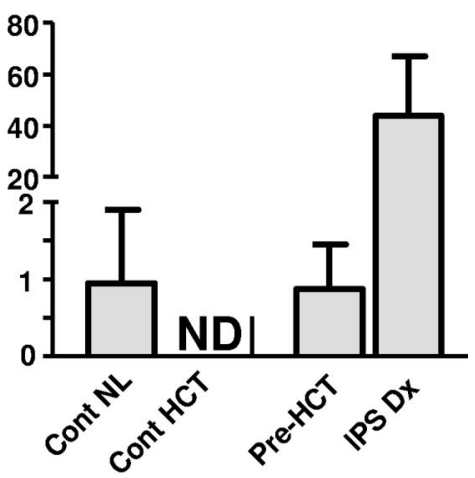

Figure 4. Plasma protein profiles. Plasma protein levels were analyzed from samples collected at the time of IPS diagnosis (IPS-Dx) and pre-BMT (IPS-Pre Dx), and also from samples collected between days 14 and 21 from allogeneic HCT recipients without complications (Cont HCT) and from healthy persons not receiving transplants (Cont $\mathrm{NL}$ ) as described in "Patient controls." Levels of several inflammatory proteins are elevated at the time of IPS. Data are expressed as mean plus or minus SEM. Significant differences between groups are shown; $\mathrm{n}=7$ to 14 per group. ND indicates not done.

(Table 3). Endothelial cell injury is well recognized after allogeneic HCT and has been implicated as a direct contributor to the development of several other transplantation-related complications, including IPS. ${ }^{45,46}$ Our group has demonstrated that experimental IPS is accompanied by significant pulmonary vascular endothelial cell apoptosis that is significantly reduced after the administration of etanercept. ${ }^{47}$ In the current study, responses to the combination of etanercept and corticosteroids were associated with a reduction in systemic cytokine concentrations and marked decreases in inflammatory protein levels in the BAL fluid, consistent with improved pulmonary vascular integrity and permeability (Table 3). Collectively, clinical and preclinical data therefore suggest that TNF- $\alpha$ may function as both an effector and facilitator of lung injury by contributing directly to endothelial cell injury and death, and regulating the chemokine milieu in the lung during the early stages of IPS. ${ }^{36,47}$

There is currently no established therapy for IPS, but standard treatment approaches include supportive care measures in conjunction with broad-spectrum antimicrobial agents with or without intravenous corticosteroids. ${ }^{4,5,8}$ Although anecdotal reports of responses to standard therapy are available, responses are limited and the mortality of patients diagnosed with IPS remains unacceptably high. ${ }^{3,4,6,8}$ Moreover, high-dose corticosteroid therapy ( $>2 \mathrm{mg} / \mathrm{kg}$ per day of methylprednisolone equivalent) has not been shown to improve outcome compared with lower doses of corticosteroids ( $\leq 2 \mathrm{mg} / \mathrm{kg}$ per day). ${ }^{6}$ Implemen- tation of advanced supportive care measures, including the use of continuous veno-venous hemofiltration, may help to improve survival in some selected patients, ${ }^{48}$ but prospective studies are lacking in the literature. The current study confirms and extends results from our initial case series in patients with IPS $^{5}$ and shows that the combination of etanercept plus corticosteroids is associated with favorable outcomes, with CRs noted in $67 \%$ of patients. Eleven of 15 patients $(73 \%)$ survived through the 28 -day study period, and $60 \%$ survived to discharge. Importantly, the time to response was rapid, with elimination of supplemental oxygen support a median of 7 days in responding patients. Importantly, aside from a single dose-limiting toxicity involving a grade 4 dermatologic event, the combination of steroids and etanercept was well tolerated. Bacteremia was noted in 3 of 15 patients, but no episodes of sepsis or concurrent fungal infections occurred while on study. Injection site reactions, commonly reported in patients with nonmalignant conditions, were not seen in this trial.

In conclusion, IPS remains a leading cause of treatment-related mortality after allogeneic HCT. The current pilot study represents an example of translational research wherein laboratory insights using established animal models of human disease were directly transformed into a novel treatment strategy for a frequently fatal clinical complication. Our data demonstrate that the addition of etanercept to standard-dose corticosteroids and supportive care measures is associated with encouraging response rates and an 
From bloodjournal.hematologylibrary.org at UNIV OF MICHIGAN on December 16, 2011. For personal use only.

Table 4. Plasma protein profiles at study onset and at completion

\begin{tabular}{|c|c|c|c|c|c|c|c|c|}
\hline & \multirow[b]{2}{*}{ No. } & \multicolumn{3}{|c|}{ TNF- $\alpha$ and soluble receptors } & \multicolumn{2}{|c|}{ Proinflammatory cytokines } & \multicolumn{2}{|c|}{ T-cell cytokines } \\
\hline & & TNF- $\alpha, p g / m L$ & TNFRI, pg/mL & TNFRII, pg/mL & IL-6, pg/mL & $\mathrm{IL}-1 \beta, \mathrm{pg} / \mathrm{mL}$ & IL-2, pg/mL & INF- $\gamma, \mathrm{pg} / \mathrm{mL}$ \\
\hline Control (NL) & 7 & $2.2 \pm 2.2$ & $999 \pm 198$ & $1722 \pm 303$ & $2.3 \pm 0.4$ & LOD & ND & $1.0 \pm 1.0$ \\
\hline Control (BMT) & 9 & $18.3 \pm 4.5$ & $1489 \pm 204$ & $4275 \pm 604$ & $7.3 \pm 2.1$ & LOD & ND & ND \\
\hline IPS-PreHCT & 12 & $16.2 \pm 3.6$ & $2043 \pm 382$ & $3415 \pm 412$ & $6.9 \pm 1.5$ & LOD & ND & $0.9 \pm 0.6$ \\
\hline IPS-Dx (All) & 14 & $63 \pm 12^{*}$ & $6257 \pm 1100^{*}$ & $15543 \pm 4137^{*}$ & $856 \pm 460^{*}$ & LOD & ND & $43.8 \pm 23.1$ \\
\hline IPS-Dx (NR) & 5 & $60 \pm 17$ & $9058 \pm 2645$ & $27267 \pm 9670$ & $947 \pm 822$ & LOD & ND & $32 \pm 12$ \\
\hline IPS-Dx (Resp) & 9 & $71 \pm 19$ & $4949 \pm 515$ & $9030 \pm 1560$ & $906 \pm 557$ & LOD & ND & $49 \pm 34$ \\
\hline \multirow[t]{3}{*}{ IPS-post (Resp) } & 9 & $119 \pm 45$ & $3000 \pm 528 \|$ & $88508 \pm 20541 \|$ & $152 \pm 60 \S$ & LOD & ND & $5.5 \pm 5.1$ \\
\hline & & \multicolumn{2}{|c|}{ LPS activation cascade } & \multicolumn{2}{|c|}{ Anti-inflammatory cytokines } & \multicolumn{3}{|c|}{ Proinflammatory chemokines } \\
\hline & & $\mathrm{sCD} 14, \mathrm{ng} / \mathrm{mL}$ & LBP, $\mathrm{ng} / \mathrm{mL}$ & IL-1ra, pg/mL & TGF- $\beta, p g / m L$ & $\mathrm{IL-8}, \mathrm{pg} / \mathrm{mL}$ & $\mathrm{CCL} 2, \mathrm{pg} / \mathrm{mL}$ & CXCL9, pg/mL \\
\hline Control (NL) & 7 & $1501 \pm 311$ & $20437 \pm 961$ & $133 \pm 32$ & $1046 \pm 547$ & $6.4 \pm 0.8$ & $386 \pm 46$ & ND \\
\hline Control (BMT) & 9 & $2414 \pm 103$ & $30768 \pm 3188$ & ND & $1178 \pm 241$ & $23.7 \pm 4.9$ & $357 \pm 65$ & $165 \pm 12.4$ \\
\hline IPS-Pre HCT & 12 & $1925 \pm 303$ & $19754 \pm 303$ & ND & $2530 \pm 735$ & $18.5 \pm 3.6$ & $348 \pm 87$ & $264 \pm 57$ \\
\hline IPS-Dx (All) & 14 & $3415 \pm 551 \dagger$ & $93353 \pm 22723^{\star}$ & $874 \pm 192 \dagger$ & $2306 \pm 492 \ddagger$ & $1008 \pm 333^{*}$ & $3317 \pm 1265^{*}$ & $1479 \pm 725^{\star}$ \\
\hline IPS-Dx (NR) & 5 & $4799 \pm 1360$ & $62353 \pm 11330$ & $1130 \pm 375$ & $2723 \pm 992$ & $531 \pm 340$ & $895 \pm 407$ & $1087 \pm 435$ \\
\hline IPS-Dx (Resp) & 9 & $2723 \pm 338$ & $110575 \pm 34144$ & $721 \pm 246$ & $1700 \pm 475$ & $1430 \pm 540$ & $5323 \pm 2100$ & $2020 \pm 1432$ \\
\hline IPS-post (Resp) & 9 & $1661 \pm 269 \|$ & $17836 \pm 2558 \|$ & $455 \pm 155$ & $1435 \pm 615$ & $549 \pm 209$ & $1670 \pm 994 \S$ & $455 \pm 137$ \\
\hline
\end{tabular}

Plasma samples were collected and plasma protein levels analyzed from all IPS patients pretransplant (IPS-PreHCT), and at the time of initial IPS diagnosis (IPS-Dx). In addition, control plasma samples were collected between day 14 and 21 after transplantation from allogeneic HCT recipients without complications (Control [BMT]), and from normal (nontransplantation) individuals (Control [NL]). No differences were observed between responders and nonresponders at the time of diagnosis, IPS-Dx (Resp) versus IPS-Dx (NR). In addition, plasma samples were collected at the time of study completion in those subjects that responded to therapy; $\mathrm{n}=7$ to 14 per group.

LOD indicates limit of detection; and ND, not done.

${ }^{*} P<.01$ IPS-Dx vs Control (NL), Control (BMT), and IPS-Pre Dx.

$\dagger P<.01$ IPS-Dx vs Control (NL) and IPS-Pre Dx only.

$\ddagger P<.01$ IPS-Dx vs Control (NL) and Control (BMT) only.

$\S P<.05$ IPS-post (Resp) vs IPS-Dx (Resp).

$\| P<.01$ IPS-post (Resp) vs IPS-Dx (Resp).

acceptable toxicity profile. Based on these favorable results, a phase 2 pediatric trial through the Children's Oncology Group and the Pediatric Blood and Marrow Transplant Consortium and a phase 3 trial through the BMT Clinical Trials Network are currently in progress.

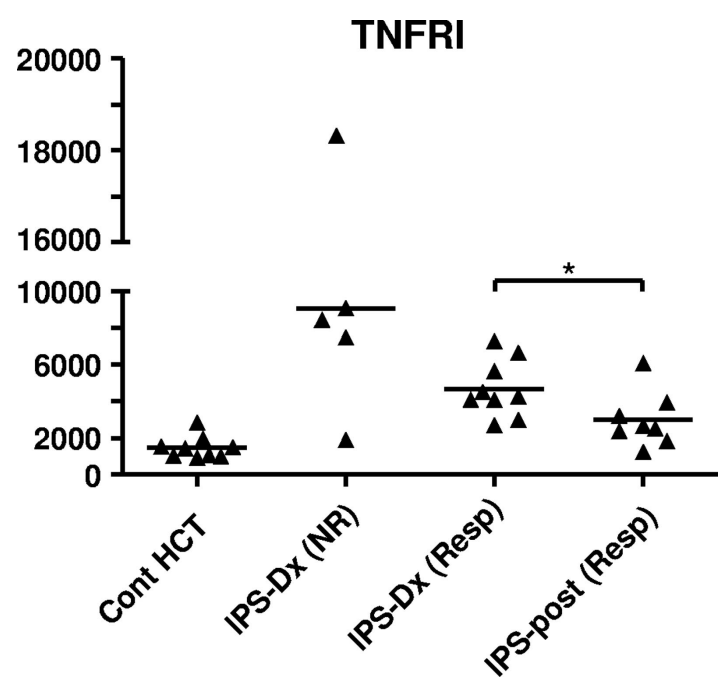

Figure 5. Plasma sTNFRI levels correlate with onset of IPS and response to therapy. Plasma sTNFRI levels were analyzed from samples collected the time of IPS diagnosis and were retrospectively categorized as responders (IPS-Dx [Resp]) or nonresponders (IPS-Dx [NR]) based on the ultimate outcome during study therapy. For responding patients, data are also provided at the end of study therapy (IPS-post [Resp]). Levels of sTNFRI are elevated at the time of IPS and return toward baseline in patients who respond to combination therapy. Data are expressed as concentration in $\mathrm{pg} / \mathrm{mL}$ for each individual sample. Significant differences between groups are shown; $\mathrm{n}=7$ to 14 per group.

\section{Acknowledgments}

This work was supported by grants from the Orphan Products Division of the Food and Drug Administration, the Leukemia \& Lymphoma Society, the Burroughs Wellcome Fund, and Immunex Corporation, Seattle, WA (now Amgen, Thousand Oaks, CA). K.R.C. is an Amy Strelzer-Manasevit Scholar of the National Marrow Program, a Fellow of the Robert Wood Johnson Harold Amos Medical Faculty Development Program, a Clinical Scholar of the Leukemia \& Lymphoma Society, and the recipient of a Clinical Scientist in Translational Research Award from the Burroughs Wellcome Fund.

\section{Authorship}

Contribution: G.A.Y., V.T.H., J.C., J.L.M.F., J.E.L., and K.R.C. designed research; G.A.Y., V.T.H., J.E.L., E.S.W., J.H.A., J.C., D.J., and K.R.C. performed research; G.A.Y., V.T.H., J.E.L., E.S.W., T.B., J.H.A., and K.R.C. analyzed data; G.A.Y., V.T.H., J.E.L., E.S.W., J.H.A., and K.R.C. wrote the paper; T.B. designed the statistical section; J.W. performed ELISA assays; and D.J. assisted with ELISA assays.

Conflict-of-interest disclosure: K.R.C. has received research support from Amgen. The remaining authors declare no competing financial interests.

Correspondence: Gregory A. Yanik, Blood and Marrow Transplantation Program, University of Michigan Medical Center, 5303 Cancer Center, 1500 East Medical Center Drive, SPC 5941, Ann Arbor, MI 48109-5941; e-mail: gyanik@umich.edu; or Kenneth R. Cooke, Case Western Reserve University School of Medicine, Department of Pediatrics, 6th Floor, Wolstein Research Building, 2103 Cornell Road, Cleveland, OH 44106-7288; e-mail: kenneth.cooke@uhhospitals.org. 
From bloodjournal.hematologylibrary.org at UNIV OF MICHIGAN on December 16, 2011. For personal use only.

\section{References}

1. Clark JG, Hansen JA, Hertz MI, Parkman R, Jensen L, Peavy HH. NHLBI workshop summary: idiopathic pneumonia syndrome after bone marrow transplantation. Am Rev Respir Dis. 1993; 147:1601-1606.

2. Clark JG, Madtes DK, Martin TR, Hackman RC, Farrand AL, Crawford SW. Idiopathic pneumonia after bone marrow transplantation: cytokine activation and lipopolysaccharide amplification in the bronchoalveolar compartment. Crit Care Med. 1999;27:1800-1806

3. Crawford SW, Hackman RC. Clinical course of idiopathic pneumonia after bone marrow transplantation. Am Rev Respir Dis. 1993;147:13931400.

4. Kantrow SP, Hackman RC, Boeckh M, Myerson $\mathrm{D}$, Crawford SW. Idiopathic pneumonia syndrome: changing spectrum of lung injury after marrow transplantation. Transplantation. 1997; 63:1079-1086.

5. Yanik G, Hellerstedt B, Custer J, et al. Etanercept (Enbrel) administration for idiopathic pneumonia syndrome after allogeneic hematopoietic stem cell transplantation. Biol Blood Marrow Transplant. 2002;8:395-400.

6. Fukuda T, Hackman RC, Guthrie KA, et al. Risks and outcomes of idiopathic pneumonia syndrome after nonmyeloablative and conventional conditioning regimens for allogeneic hematopoietic stem cell transplantation. Blood. 2003;102:27772785.

7. Cooke KR, Yanik G. Acute lung injury after allogeneic stem cell transplantation: is the lung a target of acute graft-vs-host disease? Bone Marrow Transplant. 2004;34:753-765.

8. Afessa B, Litzow MR, Tefferi A. Bronchiolitis obliterans and other late onset non-infectious pulmonary complications in hematopoietic stem cell transplantation. Bone Marrow Transplant. 2001; 28:425-434

9. Crawford S, Longton G, Storb R. Acute graft-vshost disease and the risks for idiopathic pneumonia after marrow transplantation for severe aplastic anemia. Bone Marrow Transplant. 1993;12: 225-231.

10. Bortin M, Ringden O, Horowitz M, Rozman C, Weiner R, Rimm A. Temporal relationships between the major complications of bone marrow transplantation for leukemia. Bone Marrow Transplant. 1989;4:339-344.

11. Wingard JR, Mellits ED, Sostrin MB, et al. Interstitial pneumonitis after allogeneic bone marrow transplantation: nine-year experience at a single institution. Medicine (Baltimore). 1988;67:175186.

12. Engelmann $\mathrm{H}$, Aderka $\mathrm{D}$, Rubinstein $\mathrm{M}$, Rotman D, Wallach D. A tumor necrosis factor-binding protein purified to homogeneity from human urine protects cells from tumor necrosis factor toxicity. J Biol Chem. 1989;264:11974-11980.

13. Gatanga $T$, Hwang $C$, Kohr W, et al. Purification and characterization of an inhibitor (soluble tumor necrosis factor receptor) for tumor necrosis factor and lymphotoxin obtained from the serum ultrafiltrates of human cancer patients. Proc Natl Acad Sci U S A. 1990;87:8781-8784

14. Lesback M, Hanna R, Lange JR, et al. Absolute bioavailability of TNF receptor Fusum protein following subcutaneous injection in healthy volunteers. Pharmacotherapy. 1997;17:1118.

15. Lovell DJ, Giannini EH, Reiff A, et al. Etanercept in children with polyarticular juvenile rheumatoid arthritis. N Engl J Med. 2000;342:763-769.

16. Moreland LW, Schiff MH, Baumgartner SW, et al. Etanercept therapy in rheumatoid arthritis: a randomized, controlled trial. Ann Intern Med. 1999; 130:478-486.

17. Cook DA, Dimick JB, Gallagher DC. Etanercept in rheumatoid arthritis. N Engl J Med. 1999;340: 2000-2001.

18. Andolina M, Rabusin M, Maximova N, Di Leo G. Etanercept in graft-vs-host disease. Bone Marrow Transplant. 2000;26:929.

19. Uberti JP, Ayash L, Ratanatharathorn V, et al. Pilot trial on the use of etanercept and methylprednisolone as primary treatment for acute graft-vshost disease. Biol Blood Marrow Transplant. 2005; 11:680-687.

20. Chiang KY, Abhyankar S, Bridges K, Godder K, Henslee-Downey JP. Recombinant human tumor necrosis factor receptor fusion protein as complementary treatment for chronic graft-vs-host disease. Transplantation. 2002;73:665-667.

21. Levine JE, Paczesny S, Mineishi S, et al. Etanercept plus methylprednisolone as initial therapy for acute graft-vs-host disease. Blood. 2008;111: 2470-2475.

22. Antin $\mathrm{JH}$, Weisdorf $\mathrm{D}$, Neuberg $\mathrm{D}$, et al Interleukin-1 blockade does not prevent acute graft-vs-host disease: results of a randomized, double-blind, placebo-controlled trial of interleukin-1 receptor antagonist in allogeneic bone marrow transplantation. Blood. 2002;100: 3479-3482.

23. Robbins RA, Linder J, Stahl MG, et al. Diffuse alveolar hemorrhage in autologous bone marrow transplant recipients. Am J Med. 1989;87:511518.

24. Lewis ID, DeFor T, Weisdorf DJ. Increasing incidence of diffuse alveolar hemorrhage following allogeneic bone marrow transplantation: cryptic etiology and uncertain therapy. Bone Marrow Transplant. 2000;26:539-543.

25. Metcalf JP, Rennard SI, Reed EC, et al. Corticosteroids as adjunctive therapy for diffuse alveolar hemorrhage associated with bone marrow transplantation: University of Nebraska Medical Center Bone Marrow Transplant Group. Am J Med. 1994; 96:327-334.

26. Majhail NS, Parks K, Defor TE, Weisdorf DJ. Diffuse alveolar hemorrhage and infectionassociated alveolar hemorrhage following hematopoietic stem cell transplantation: related and high-risk clinical syndromes. Biol Blood Marrow Transplant. 2006;12:1038-1046.

27. Capizzi SA, Kumar S, Huneke NE, et al. Periengraftment respiratory distress syndrome during autologous hematopoietic stem cell transplantation. Bone Marrow Transplant. 2001;27:12991303.

28. Cahill RA, Spitzer TR, Mazumder A. Marrow engraftment and clinical manifestations of capillary leak syndrome. Bone Marrow Transplantation. 1996;18:177-184.

29. Weiner RS, Horowitz MM, Gale RP, et al. Risk factors for interstitial pneumonitis following bone marrow transplantation for severe aplastic anemia. Br J Haematol. 1989;71:535-543.

30. Down JD, Mauch P, Warhol M, Neben S, Ferrara JLM. The effect of donor T lymphocytes and totalbody irradiation on hemopoietic engraftment and pulmonary toxicity following experimental allogeneic bone marrow transplantation. Transplantation. 1992;54:802-808.

31. Shankar G, Cohen DA. Idiopathic pneumonia syndrome after bone marrow transplantation: the role of pre-transplant radiation conditioning and local cytokine dysregulation in promoting lung inflammation and fibrosis. Int J Exp Pathol. 2001; 82:101-113.

32. Panoskaltsis-Mortari A, Taylor PA, Yaegar TM, et al. The critical early proinflammatory events associated with idiopathic pneumonia syndrome in irradiated murine allogenic recipients are due to donor T cell infusion and potentiated by cyclophosphamide. J Clin Invest. 1997;100:10151027.
33. Cooke KR, Kobzik L, Martin TR, et al. An experimental model of idiopathic pneumonia syndrome after bone marrow transplantation: I. The roles of minor $\mathrm{H}$ antigens and endotoxin. Blood. 1996;88: 3230-3239.

34. Shankar G, Scott Bryson J, Darrell Jennings C, Kaplan AM, Cohen DA. Idiopathic pneumonia syndrome after allogeneic bone marrow transplantation in mice: role of pretransplant radiation conditioning. Am J Respir Cell Mol Biol. 1999;20: 1116-1124.

35. Piguet PF, Grau GE, Collart MA, Vassalli P, Kapanci Y. Pneumopathies of the graft-vs-host reaction: alveolitis associated with an increased level of tumor necrosis factor MRNA and chronic interstitial pneumonitis. Lab Invest. 1989;61:3745.

36. Hildebrandt GC, Olkiewicz KM, Corrion LA, et al. Donor-derived TNF-alpha regulates pulmonary chemokine expression and the development of idiopathic pneumonia syndrome after allogeneic bone marrow transplantation. Blood. 2004;104: 586-593.

37. Piguet PF, Grau GE, Allet B, Vassalli PJ. Tumor necrosis factor/cachectin is an effector of skin and gut lesions of the acute phase of graft-vshost disease. J Exp Med. 1987;166:1280-1289.

38. Cooke KR, Hill GR, Gerbitz A, et al. Tumor necrosis factor-alpha neutralization reduces lung injury after experimental allogeneic bone marrow transplantation. Transplantation. 2000;70:272-279.

39. Cooke KR, Hill GR, Gerbitz A, et al. Hyporesponsiveness of donor cells to lipopolysaccharide stimulation reduces the severity of experimental idiopathic pneumonia syndrome: potential role for a gut-lung axis of inflammation. J Immunol. 2000; 165:6612-6619.

40. Brockhaus M, Schoenfeld HJ, Schlaeger EJ, Hunziker W, Lesslauer W, Loetscher H. Identification of two types of tumor necrosis factor receptors on human cell lines by monoclonal antibodies. Proc Natl Acad Sci U S A. 1990;87:31273131.

41. Loetscher H, Pan YC, Lahm HW, et al. Molecular cloning and expression of the human $55 \mathrm{kd}$ tumor necrosis factor receptor. Cell. 1990;61:351-359.

42. Schall TJ, Lewis M, Koller KJ, et al. Molecular cloning and expression of a receptor for human tumor necrosis factor. Cell. 1990;61:361-370.

43. Hildebrandt GC, Duffner UA, Olkiewicz KM, et al A critical role for CCR2/MCP-1 interactions in the development of idiopathic pneumonia syndrome after allogeneic bone marrow transplantation. Blood. 2004;103:2417-2426.

44. Hildebrandt GC, Olkiewicz KM, Corrion LA, et al. A role for TNF receptor type II in leukocyte infiltration into the lung during experimental idiopathic pneumonia syndrome. Biol Blood Marrow Transplant. 2008;14:385-396.

45. Janin A, Deschaumes C, Daneshpouy M, et al CD95 engagement induces disseminated endothelial cell apoptosis in vivo: immunopathologic implications. Blood. 2002;99:2940-2947.

46. Salat C, Holler E, Kolb HJ, Reinhardt B, Pihusch R. Plasminogen activator inhibitor-1 confirms the diagnosis of hephatic veno-occlusive disease in patients with hyperbilirubinemia after bone marrow transplantation. Blood. 1997;89:2184-2188.

47. Gerbitz A, Nickoloff BJ, Olkiewicz K, et al. A role for tumor necrosis factor-alpha-mediated endothelial apoptosis in the development of experimental idiopathic pneumonia syndrome. Transplantation. 2004;78:494-502.

48. DiCarlo JV, Alexander SR, Agarwal R, Schiffman JD. Continuous veno-venous hemofiltration may improve survival from acute respiratory distress syndrome after bone marrow transplantation or chemotherapy. J Pediatr Hematol Oncol. 2003; 25:801-805 